\title{
Study on the Reserve Structrue of Light Weapons
}

\author{
Jian $\mathrm{Gao}^{1}$, Tielin Liu ${ }^{1}$ and Liang Zhang ${ }^{2}$ \\ ${ }^{1}$ Department of Equipment Command and Administration Army Engineering University, Shijiazhuang, China \\ ${ }^{2}$ Unit 65154 PLA, Chaoyang, China
}

\begin{abstract}
In view of the lack of pertinence in the weapon equipment maintenance capability evaluation, combining the characteristics of light weapon equipment, the evaluation index model of light weapon maintenance capability is established. The importance of each index in the light weapon maintenance process is compared, and the weight of each index is obtained by AHP. Finally, the rationality of the evaluation results is analyzed according to the current situation of the light weapon maintenance and the characteristics of the equipment.
\end{abstract}

Keywords_light weapon; equipment support; evaluation

\section{INTRODUCTION}

The maintenance of light weapons is an effective method to maintain and restore its technical performance. It is of great significance to strengthen the maintenance support capability of light weapons in order to ensure the combat and combat readiness training of the armed forces[1].

At present, the evaluation indexes of equipment maintenance ability which can not effectively reflect the importance of each index in the evaluation process, are complicated and have inconsistent standards. The evaluation process can not truly reflect the quality of equipment maintenance support capability, and lacks guidance significance for strengthening the construction of maintenance support capability. In addition, our army lacks the maintenance support capability evaluation in light of the light weapon characteristics. The measures to strengthen the maintenance support capability of light weapons also lack the corresponding basis and have certain blindness.

In order to reasonably evaluate the maintenance support capability of light weapon, an evaluation index model suitable for the maintenance of light weapon equipment is established. AHP is used to evaluate the maintenance support capability of light weapons, to determine the future direction and construction of light weapon maintenance support and provide scientific reference for improving the maintenance support capability of light weapon.

\section{RELATED CONCEPTS}

Equipment maintenance support is to maintain and restore the military equipment intact state of technology and improve equipment performance, which collectively carry out combat training and other tasks, and take technical measures and organize the implementation of the security activities[2].

The maintenance support of light weapon equipment is the technical guarantee and management activities of the light weapons from the beginning of the equipment unit until the scrap or eliminated so as to maintain its good technical condition and prolong its service life[3].
Through the analysis of the factors affecting the maintenance support capability, the qualitative and quantitative methods are used to make a comparative study of the importance of each factor, so as to objectively evaluate the maintenance level of the light weapons[4].

\section{A. Evaluation Index Model}

The factors affecting the maintenance support capability of weapon equipment are quite complex. Therefore, combining the characteristics of light weapons, establishing a reasonable index model is the premise and key for effective evaluation.

As an important factor in the combat effectiveness of infantry, light weapons have the characteristics of small caliber, light weight, all-weather operation capability and so on. The light weapons and equipment of our army are developing rapidly, updating rapidly, and the new and old equipment coexist, and the gap between the spectrums is obvious. Among them, the main battle gear has high reliability, strong adaptability, difficult maintenance and short cycle, but requires higher accuracy of spare parts. In view of the above characteristics of the light weapon equipment, combined with the model practicability and operability requirements, the article takes scientific, completeness, independence and comparability as the important basis of the index, extensively consults the experts, and discusses the influencing factors of the index system in depth, so as to determine the relevant indicators.

First of all, the actual maintenance process of light weapons is analyzed from the view of executor, execution mode, external conditions and management guarantee. The factors affecting the maintenance support capability of the light weapon equipment are decomposed into 4 first level indicators: light weapon maintenance personnel who play a major role in the maintenance process, all kinds of light weapons maintenance equipment operated during the maintenance process, replacement of spare parts for light weapons when troubleshooting and the level of maintenance operation. Then, from the view of quantity and quality, supply and adaptability, technical guarantee and system guarantee, the system hierarchy theory is used[5]. The four first level indicators are further refined into 9 objective second level indicators for comprehensive evaluation, and a specific evaluation index system model is established, as shown in figure 1 . 


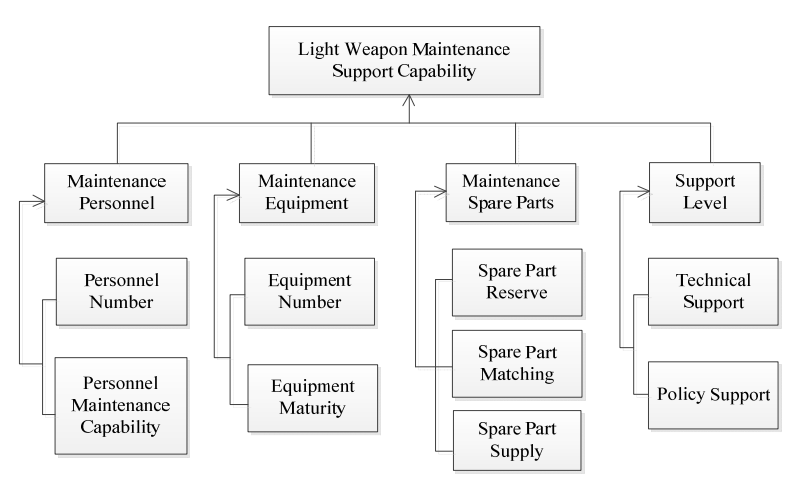

FIGURE I. MODEL OF MAINTENANCE SUPPORT EVALUATION INDEX

First of all, the impact of light weapons maintenance personnel mainly depends on the number of personnel, personnel maintenance capabilities, and judging the personnel maintenance ability is mainly through personnel professional skills, professional matching, proficiency and so on. Compared with other high-tech weaponry, the maintenance of light weapons is not very difficult, and there are not many teams involved in the maintenance of light weapons. So the efficiency of group personnel coordination is neglected to enhance the practicability and pertinence of the model.

The impact of light weapons maintenance equipment mainly depends on the number of maintenance equipment and the maturity of maintenance equipment. The maturity of maintenance equipment refers to the modern level of maintenance equipment, the difficulty of operation and the durability of equipment. Because of the high reliability and strong adaptability of the main battle light weapons, the daily maintenance equipment has good versatility in different spectrum equipment, so it ignores the influence of the matching of maintenance equipment.

The spare parts for the maintenance of light weapons mainly depend on the reserve of spare parts and the allocation, supplement and supply capacity of the spare parts. Because of the high precision of the spare parts, the specialty and pertinence of the light weapons, the influence of the matching of spare parts should be considered comprehensively.

The level of support capability mainly depends on technical guarantee and system guarantee. Among them, technical guarantee refers to the completeness and applicability of technical information and the matching degree of related information. The system guarantee is determined by the formulation, implementation and guarantee of the system, the allocation of manpower and material resources et.

\section{EXAMPLE OF CALCUlation PRocess}

The relative importance of the indicators was compared by scoring 4 first level indicators and 9 second level indicators for the maintenance support capability of light weapons. The judgment matrix is constructed and normalized, and the relative weights of each factor in the group are calculated as follows.
TABLE I. INFLUENCE FACTOR WEIGHT OF MAINTENANCE SUPPORT CAPABILITY

\begin{tabular}{|c|c|c|c|c|c|}
\hline $\begin{array}{c}\text { Maintenance } \\
\text { support } \\
\text { Capability }\end{array}$ & $\begin{array}{c}\text { Maintenance } \\
\text { Equipment }\end{array}$ & $\begin{array}{c}\text { Maintenance } \\
\text { spare parts }\end{array}$ & $\begin{array}{c}\text { Support } \\
\text { level }\end{array}$ & $\begin{array}{c}\text { Maintenance } \\
\text { personnel }\end{array}$ & Wi \\
\hline $\begin{array}{c}\text { Maintenance } \\
\text { Equipment }\end{array}$ & 1.0000 & 0.2500 & 3.0000 & 0.5000 & 0.1504 \\
\hline $\begin{array}{c}\text { Maintenance } \\
\text { spare parts }\end{array}$ & 4.0000 & 1.0000 & 5.0000 & 3.0000 & 0.5349 \\
\hline \begin{tabular}{c} 
Support level \\
\hline $\begin{array}{c}\text { Maintenance } \\
\text { personnel }\end{array}$
\end{tabular} & 0.3333 & 0.2000 & 1.0000 & 0.2500 & 0.0691 \\
\hline
\end{tabular}

Consistency ratio: $0.0186 ; \lambda \max =4.0497$

TABLE II. INFLUENCE FACTOR WEIGHT OF MAINTENANCE PERSONNEL

\begin{tabular}{|c|c|c|c|}
\hline $\begin{array}{c}\text { Maintenance } \\
\text { Personnel }\end{array}$ & Number & Capability & Wi \\
\hline Number & 1.0000 & 3.0000 & 0.7500 \\
\hline Capability & 0.3333 & 1.0000 & 0.2500 \\
\hline \multicolumn{4}{|c|}{ Consistency ratio: $0.0000 ; \lambda \max =2.0000$} \\
\hline
\end{tabular}

TABLE III. INFLUENCE FACTOR WEIGHT OF MAINTENANCE EQUIPMENT

\begin{tabular}{|c|c|c|c|}
\hline $\begin{array}{c}\text { Maintenance } \\
\text { Equipment }\end{array}$ & Number & Maturity & Wi \\
\hline Number & 1.0000 & 3.0000 & 0.7500 \\
\hline Maturity & 0.3333 & 1.0000 & 0.2500 \\
\hline
\end{tabular}

Consistency ratio: $0.0036 ; \lambda \max =3.0037$

TABLE IV. INFLUENCE FACTOR WEIGHT OF MAINTENANCE SPARE PARTS

\begin{tabular}{|c|c|c|c|c|}
\hline $\begin{array}{c}\text { Maintenance } \\
\text { Spare Parts }\end{array}$ & Supply & Matching & Reserve & Wi \\
\hline Supply & 1.0000 & 2.0000 & 0.3333 & 0.2297 \\
\hline Matching & 0.5000 & 1.0000 & 0.2000 & 0.1220 \\
\hline Reserve & 3.0000 & 5.0000 & 1.0000 & 0.6483 \\
\hline
\end{tabular}

Consistency ratio: $0.0000 ; \lambda \max =2.0000$

TABLE V. INFLUENCE FACTOR WEIGHT OF SUPPORT LEVEL

\begin{tabular}{|c|c|c|c|}
\hline Support & Technical & Policy & Wi \\
\hline Technical & 1.0000 & 1.0000 & 0.5000 \\
\hline Policy & 1.0000 & 1.0000 & 0.5000 \\
\hline \multicolumn{3}{|c|}{ Consistency ratio: $0.0000 ; \lambda \max =2.0000$}
\end{tabular}

The contrast weights between the second level indicators are combined with the weights of the first level index of the group, and then the consistency test is carried out. Finally, the influence weights of the 9 second level indicators relative to the total target are obtained[6].

\section{Evaluation Result AND AnAlysis}

Through calculation, in the 9 second level indicators affecting the maintenance support capability of light weapons, the maintenance reserve of light weapons has the biggest impact, accounting for $34.68 \%$; The number of maintenance personnel, the supply capacity of spare parts and the number of maintenance equipment are secondary, accounting for $18.42 \%, 12.28 \%$ and $11.28 \%$ respectively; Maintenance 
personnel professional capacity, maintenance equipment maturity and technical, institutional guarantee influence is not much, accounting for no more than $10 \%$. Through analysis, the importance order of each factor is consistent with the actual maintenance of our army's light weapons maintenance in the new period and new stage.

First of all, with the continuous development and progress of our military equipment industry, the reliability and adaptability of light weapons are becoming stronger and stronger, and it is possible to ensure certain performance is maintained without losing basic functionality when the damage is low[7]. In the battlefield or other extreme environment, when the light weapons are damaged and performance is affected, through direct replacement of the relevant parts of the spare parts, Rapid recovery performance has become the most important way to support the maintenance of light weapons. The maintenance personnel will repair the replaced damaged parts according to the situation in subsequent assignments. Therefore the light weapon spare parts supply capacity affects the maintenance work to a great extent. It can be believed that with the further change of the battlefield environment in the future and the continuous progress of equipment development and manufacture in our country, the equipment integration and modularization are becoming more and more high, and most of the module damage that does not affect the main function will increasingly rely on the replacement of spare parts so as to restore the performance index in the shortest possible time[8].

Secondly, the number of maintenance personnel and equipment, which plays a major role in the maintenance support capability in the traditional concept, has not played a decisive role in the current maintenance support process due to the relatively simple maintenance process of light weapons and the low difficulty of operation and the complexity of maintenance equipment. Similarly, when our military equipment maintenance personnel level of education, operational ability and other comprehensive qualities continue to improve, the influence of maintenance personnel's professional ability, equipment maturity and related factors on the maintenance are gradually decreasing for the maintenance of light weapons with lower maintenance difficulty and better maintenance equipment.

\section{SUMMARY}

Nowadays, most of the traditional equipment maintenance support evaluations aim to establish a "universal and comprehensive" index model, hoping to use one single model to evaluate the maintenance support capability of multiple equipment. Unfortunately, the practicability of the model is restricted by its lack of applicability. Closely combined with the characteristics of light weapons, a model which draws lessons from the practice of light weapons maintenance process, is established in the article. The assessment results which fully reflect the current situation of the light weapon maintenance support capability, have referential significance for the construction and improvement of the capability.

\section{REFERENCES}

[1] Liu Junqing. "Foundation for the maintenance and management of light weapons" Wuhan: Ordnance Officer School Press, 2007.
[2] General Equipment Department General Planning Department. "Military Equipment Technical Support" Beijing: People's Liberation Army Press, 2006.

[3] Duan Fang. "Research on the contribution rate of infantry based light weapon equipment system" Shijiazhuang: Ordnance Engineering College, 2016.

[4] Hu Jianbo. "Introduction to military equipment maintenance support technology" Beijing: PLA press, 2010.

[5] ZHANG Xiao-hua, LIU Ming-yun, WANG Guo-shi, et al. "Evaluation of Maintenance Support Ability of Tianbo Radar Based on AHP" Fire and Command \& Control, 2014, 39 (12): 145-152.

[6] WANG Wei-yu, ZHU Lian-jun. "Evaluation of Command and Control Effectiveness of Equipment Support Command Information System Based on AHP-Fuzzy" Journal of Ordnance Equipment Engineering, 2016, 37 (10): 66-71.

[7] Zhang Chang. "Study on the law of spare parts consumption of new equipment for light weapons" Shijiazhuang: Ordnance Engineering College, 2004.

[8] Wang Mingliang, Yu Bobiao. "Armored equipment warehouse spare parts inventory optimization method" Ordnance Automation, 2013, 32 (8): $21-24$ 